\title{
A Network Explanation of Alzheimer's Regional Vulnerability
}

\author{
Scott A. SMall ${ }^{1}$ AND LaRry W. Swanson ${ }^{2}$ \\ ${ }^{1}$ Department of Neurology and the Taub Institute for Research on Alzheimer's Disease and the Aging \\ Brain and Department of Neurology, Columbia University, New York, New York 10027, USA \\ ${ }^{2}$ Department of Biological Sciences, University of Southern California, Los Angeles, \\ California 90007, USA \\ Correspondence: sas68@columbia.edu; larryswanson10@gmail.com
}

\begin{abstract}
Studies in patients and mouse models have pinpointed a precise zone in the cerebral cortex selectively vulnerable to the earliest stages of Alzheimer's disease (AD): the borderzone covering the entorhinal and perirhinal cortical areas. An independent series of studies has revealed that this entorhinal-perirhinal borderzone is a central cortical hub, with a distinct connectivity pattern across the cerebral hemispheres. Here we develop a hypothesis that explains how this distinct network feature interacts with established pathogenic drivers of AD in explaining the disease's regional vulnerability and suggests how it acts as an anatomical source of disease spread.
\end{abstract}

The first indication that the entorhinal area of the cerebral cortex is differentially vulnerable to Alzheimer's disease (AD) was reported more than 40 years ago (Ball 1978). Since then numerous postmortem, neuroimaging, and cognitive studies have validated this localization as fact. Nevertheless, the mechanisms underlying this remarkable pattern of vulnerability have remained elusive.

The entorhinal area itself is made up of different subregions, and a convergence of findings have pinpointed precisely where AD begins. This precise entorhinal subregion, highly vulnerable to $\mathrm{AD}$, turns out to have unique network properties. Here we incorporate these network properties together with known pathogenic mechanisms of the disease to develop a hypothesis that explains AD's anatomical vulnerability and that explains the established anatomical pattern of disease spread.

As will be reviewed, the hypothesis is supported by a number of observations regarding the molecular, cellular, and anatomical pathology of the disease. At the same time, the hypothesis makes a number of experimentally tractable predictions that have not yet been tested. Future studies will be able to test these predictions, thereby refuting or supporting the hypothesis.

\section{THE ENTORHINAL-PERIRHINAL BORDERZONE IS DIFFERENTIALLY VULNERABLE TO DISEASE}

Histologically, AD is characterized by the accumulation of cleaved fragments of the amyloid precursor protein (APP), in particular A $\beta$ peptides, and of aggregations of the microtubule-binding protein tau (Braak and Braak 1991). These abnormalities are typically, and somewhat simplistically, termed amyloid pathology and tau pathol- ogy. Cytologically, AD is typified first by synaptic loss and then by neuronal death (Selkoe 2002), a defining feature of neurodegeneration.

Mapping these four hallmark pathophysiological features has been used to pinpoint the brain's regions differentially vulnerable to AD. A chronically progressive disorder, AD starts locally and then, over the course of years, spreads to neighboring regions and ultimately throughout most of the cortical mantle. Mapping earliest sites of vulnerability in postmortem brains, therefore, requires performing autopsies in patients in the earliest disease stage, which is often unclear at the time of death. In vivo neuroimaging tools designed to detect these early hallmark features can address this limitation, but compared to postmortem analysis these tools visualize the hallmarks with less precision. Postmortem and in vivo studies thus complement each other in mapping AD.

When viewed collectively, the numerous postmortem (e.g., Gómez-Isla et al. 1996; Lue et al. 1999; Braak et al. 2006) and in vivo studies (e.g., Khan et al. 2014; Schöll et al. 2016; Tward et al. 2017) mapping the hallmark features of AD converge on the entorhinal area of cortex as the brain region differentially vulnerable to the earliest stages of AD. Cognitive studies support this conclusion by showing that mild deficits in neuropsychological tests that localize to the entorhinal area (Brickman et al. 2010) are those affected first and foremost in the earliest stages of AD (Elias et al. 2000).

"Amyloid pathology" is the one hallmark feature for which there is some discordance. The easiest and most reliable approach for mapping amyloid pathology is by visualizing extracellular, fully formed, amyloid plaques. But it is now understood that $\mathrm{A} \beta$, the core of extracellular plaques is first produced inside neurons, and then secreted as soluble species, before serving as the nidus for plaque

(C) 2018 Small and Swanson. This article is distributed under the terms of the Creative Commons Attribution-NonCommercial License, which permits reuse and redistribution, except for commercial purposes, provided that the original author and source are credited. 

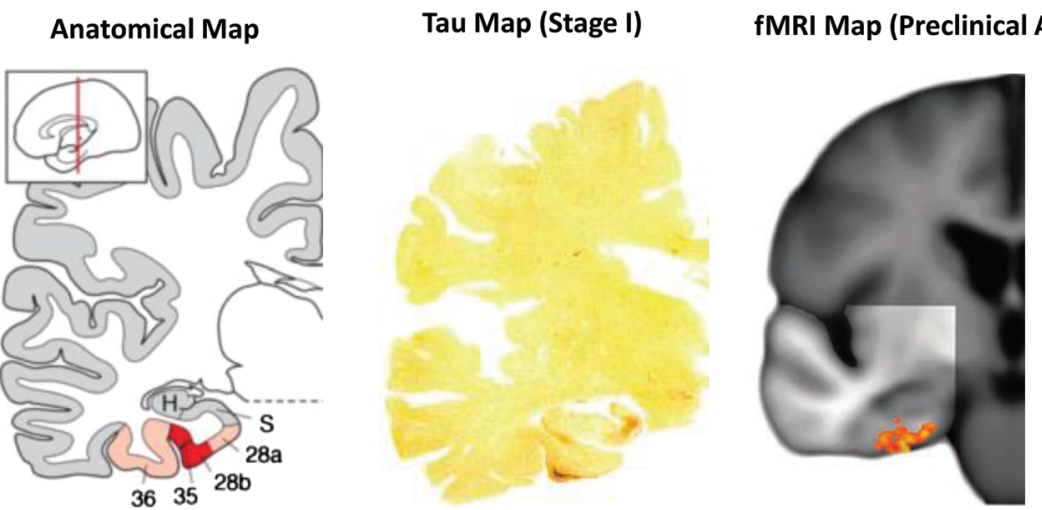

Figure 1. The entorhinal-perirhinal borderzone (EPBZ) is differentially vulnerable to Alzheimer's disease (AD). (Left) The EPBZ (red) is a tiny zone of the cerebral cortex that is centered in the lateral half of the parahippocampal gyrus and includes the lateral entorhinal area (28b) and perirhinal area (35). The EPBZ is flanked medially (light red) by the medial entorhinal area (28a) and is flanked laterally (light red) by the ectorhinal area (36). (Middle) Tau staining in a postmortem brain slice in a person with early stages of AD. Note the staining in the EPBZ, which in the clinical literature has been called the transentorhinal cortex. (Reprinted from Braak et al. 2003.) (Right) An fMRI brain slice from a patient with documented preclinical AD. Pixels with significantly reduced cerebral blood volume (a proxy measure of metabolism), compared to an age-matched control were found localized to the EPBZ. (Reprinted, with permission, from Khan et al. 2014.)

formation (for review, see Small et al. 2017). It is these nonplaque forms of $A \beta$ that are believed to be most neurotoxic (Selkoe 2002). Interestingly, maps of amyloid plaques have little anatomical regionality, with widespread cortical distribution observed in even the earliest stages of disease (Braak and Braak 1991; Sperling et al. 2014). This anatomical discordance with the manner in which AD starts and spreads clinically, and with other clear pathological indictors - tau pathology, synaptic and neuronal loss - provides the strongest support for the view that amyloid plaques are not causal drivers of the disease. Although mapping the nonplaque and neurotoxic forms of $A \beta$ is challenging, studies have shown that intraneuronal (Gouras et al. 2010) and soluble A $\beta$ (Lue et al. 1999; Tomic et al. 2009) can accumulate differentially in the entorhinal area.

The entorhinal area itself is made up of different subregions (Boccara et al. 2015). Where precisely in the entorhinal area does $\mathrm{AD}$ begin? When examined more carefully, and when resolution permits, postmortem and in vivo maps of AD's hallmarks have answered this question by pinpointing AD's "ground zero" (Yassa 2014) at the borderzone covering lateral parts of the entorhinal area and the adjacent perirhinal area (Fig. 1; Braak et al. 2006; Khan et al. 2014; Tward et al. 2017; Maass et al. 2018). In the clinical literature this region has been called the "transentorhinal cortex," which is not conventional terminology commonly used in neuroanatomical studies of humans and other mammals. In an effort at greater harmonization, we suggest the more conventional and descriptive term, the "entorhinal-perirhinal borderzone" (EPBZ).

\section{THE ENTORHINAL-PERIRHINAL BORDERZONE HAS A DISTINCT PATTERN OF CONNECTIVITY}

The global pattern of axonal connections from one cortical region to another (macroconnections, as from lateral entorhinal area to dentate gyrus or from dentate gyrus to field CA3) has recently been subjected to formal network analysis in the rat, in which the only nearly complete data set based on experimental pathway tracing methods exists for mammals (Fig. 2; Swanson et al. 2017). All 77 cortical regions recognized in each hemisphere of a standard rat brain atlas (Swanson 2018) were included in the analysis, and the entorhinal area and immediately surrounding areas emerged as the single most highly interconnected zone of the cortical mantle. Four features of the connectivity pattern suggest possible mechanisms involved in the pathogenesis of $\mathrm{AD}$ (Fig. 2).

First, the lateral entorhinal area (Brodmann area 28a) has input connections from more different cortical areas than any other part of the cortical mantle (it has the highest input degree of any cortical region). Second, the lateral entorhinal area and laterally adjacent perirhinal area (Brodmann area 35) together form one of two so-called central rich clubs of the cerebral hemispheres. The basic idea of a rich club is simple: it is a group of hubs that interconnect with each other much more than they interconnect with other hubs. The term comes from the observation that small groups of very wealthy individuals tend to interact with each other (forming a "club") much more than they interact with certain other wealthy people or with the "lower classes." A clear functional implication of this network feature is that damage to a rich club (e.g., the EPBZ) would be expected to have the greatest deleterious effect on overall network functioning. The second cortical rich club is in the frontal region and includes an anatomically continuous zone consisting of the premotor and orbitofrontal areas.

Third, there are five top-level hubs in the bilateral cerebral cortical network of association and commissural macroconnections, and surprisingly they form an anatomically compact zone that is centered on the lateral entorhinal and perirhinal areas. This zone also includes three adjacent regions: medial entorhinal area (medially; Brodmann's area 28b), ectorhinal area (laterally; Brodmann's area 35 ), and posterior basolateral amygdalar nucleus (rostrally). 

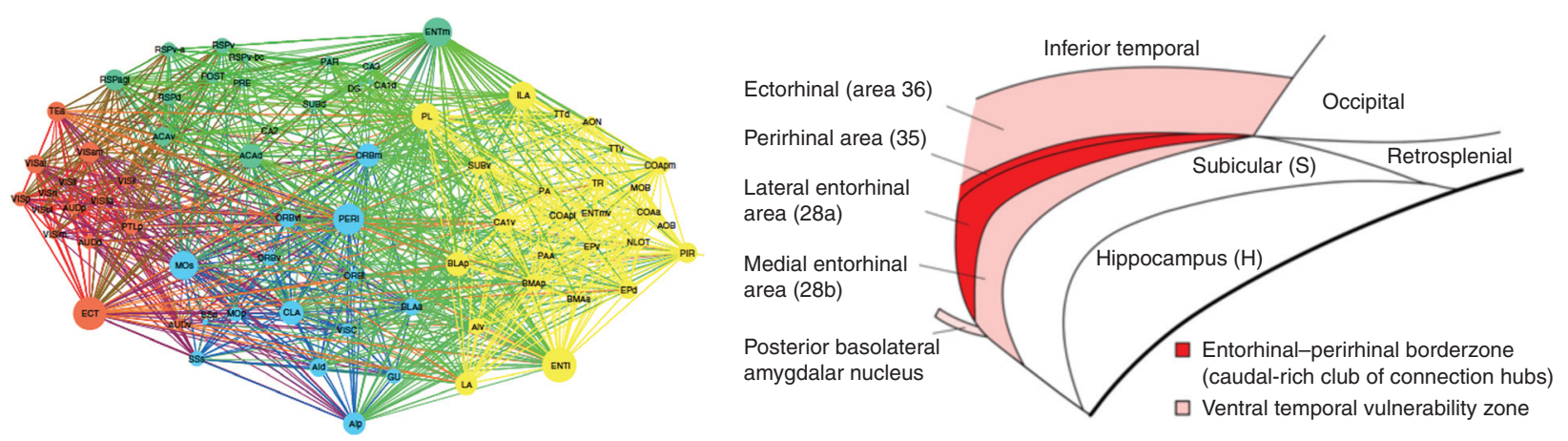

Figure 2. The EPBZ has the highest brain connectivity. (Left) The axonal macroconnections between all gray matter regions on one side of the rat cerebral cortex - the cortical association connection network. The results are shown as a force-directed graph in which connections are grouped into highly interconnected subsystems (indicated by yellow, blue, green, and red) based on the number of connections associated with each gray matter region (node in the graph, with the number of connections reflected in the diameter of the node). Note that each of the four subsystems has at least one of five gray matter regions comprising the ventral temporal vulnerability zone - that is, nodes with the greatest connectivity and thus largest diameter (PERI, ENTl, ENTm, ECT, BLAa). This is a nontopographical representation of the network, in which the spatial location of nodes is determined by connection strength. This version 1.0 of the cortical association network is reprinted with permission from Bota et al. (2015). (Right) Flatmap representation of the EPBZ (red) and ventral temporal vulnerability zone (VTVZ; red and light red together) and their spatial relationship to surrounding cortical regions. Note that the posterior basolateral amygdalar nucleus is included in the VTVZ because it is one of the five top-ranked cortical hubs, along with the lateral and medial entorhinal, perirhinal, and ectorhinal areas. Topological border relationships for the cortical territory shown in the figure are fundamentally similar in rodents and human (Swanson 2018). The anatomical terms used in the figure are defined in Swanson (2015).

Together, the five parts of this "superhub," which we tentatively call the ventral temporal vulnerability zone (VTVZ), receive macroconnection inputs from virtually the entire cortical mantle. And fourth, the vast majority of macroconnections within the association and commissural cortical network use glutamate as a neurotransmitter.

The presumably same five cortical regions are found in ventral and medial temporal regions of the human cortex, and the topological relationships between their boundaries appear to be the same as in rat (Swanson 2018).

\section{A NETWORK EXPLANATION FOR ALZHEIMER'S REGIONAL VULNERABILITY}

In this section, we will develop a hypothesis for how the distinct network properties of the entorhinal and perirhinal cortical areas interact with established pathogenic drivers of $\mathrm{AD}$ in explaining regional vulnerability. We start with the assumption that chronic levels of synaptic activity in a population of neurons is influenced by the density and diversity of its afferent inputs (input connections). Empirical findings support this assumption (Stepanyants et al. 2002), as do the fundamental principles of synaptic biology. Accordingly, it is plausible to assume that, chronically integrated across life, neurons in the EPBZ experience differentially high synaptic activity and potentially high activity-dependent plasticity.

The neuronal consequences of high synaptic activity interact with the mechanisms for how $A \beta$ is produced and secreted from neurons. The $A \beta$ peptide is liberated from its parent protein, the APP, via two enzymatic steps. The original formulation that APP is cleaved at the neuronal cell membrane turns out to be wrong (Small and Gandy 2006). The dominant proteolytic cleavage of APP occurs primarily at endosomal membranes, and it is in endosomes in which $\mathrm{A} \beta$ accumulates inside neurons (Fig. 3; for review, see Small and Gandy 2006). A $\beta$ is thought to be secreted from neurons via the endosomal system, when the late endosome-multivesicular body (MBV) fuses with the neuronal cell membrane, releasing its contents into the extracellular space (Fig. 3; Rajendran et al. 2006).

Synaptic activity has two consequences. First, because synaptic activity accelerates the endocytosis of cell surface APP it accelerates $A \beta$ production by increasing the levels of APP in endosomes (Cirrito et al. 2008). Second, the calcium influx induced by synaptic activity accelerates MBV fusion with the cell surface (Savina et al. 2005), increasing the secretion of its contents.

Mutations in APP or the presenilins, proteins that are part of the multiprotein gamma secretase, cause a rare earlyonset form of AD (Hardy and Selkoe 2002). These mutations influence the intraneuronal processing of APP, leading to an absolute or relative increase in $\mathrm{A} \beta 42$, a fragment that at abnormal concentrations is particularly neurotoxic. Neither APP nor the genes that encode its cleaving enzymes are differentially expressed in the entorhinal area. We hypothesize that the reason the EPBZ is vulnerable to this early-onset form of the disease is because its high chronic activity rates synergize with these mutations, accelerating intraneuronal $\mathrm{A} \beta$ production and secretion. When at high levels both events are shown to be neurotoxic.

How about the much more common late-onset form of $\mathrm{AD}$ ? Recent studies have established that a pathogenic driver of the more common late-onset forms of the disease is defective endosomal trafficking (Small et al. 2017). Some of the best evidence in support of this conclusion is provided by molecules related to retromer, a multimodular protein assembly that functions in sorting and trafficking cargo out of the endosome (Small and Petsko 2015). For example, mutations in SORL1, encoding a key retromer receptor 
Low Connectivity

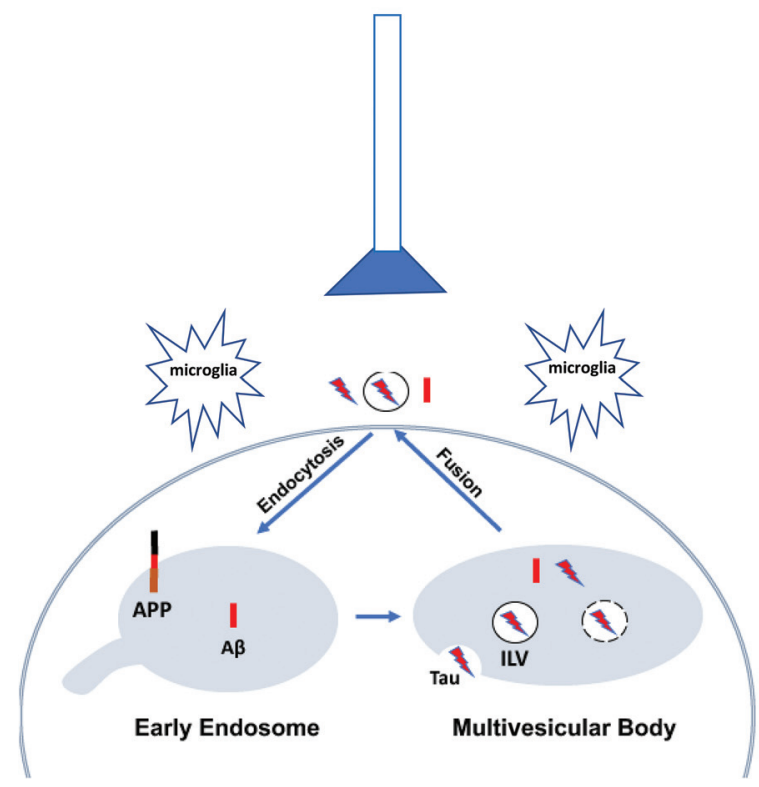

High Connectivity

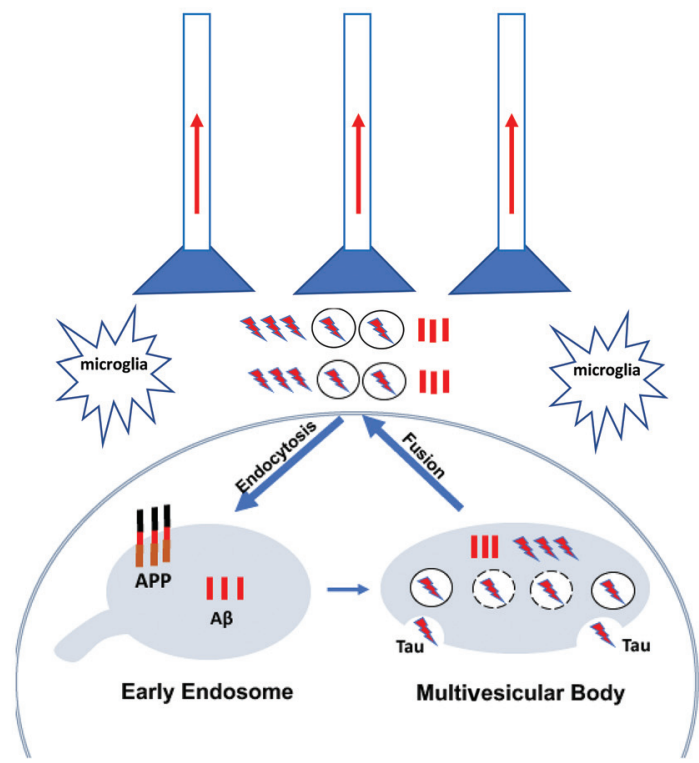

Figure 3. High connectivity interacts with Alzheimer's pathogenic drivers. (Left) Activity-dependent endocytosis of the amyloid precursor protein (APP) concentrates APP in the early endosomes. The early endosome is the cleavage site of APP, liberating its $\mathrm{A} \beta$ peptide into the endosomal lumen. Early endosomes mature into the multivesicular body (MVB). During this maturation intralumenal vesicles are formed, scooping up cytosolic proteins, including tau. Intraluminal vesicles (ILVs) can release their content into the MVB lumen. MVBs fuse with the cell membrane in an activity-dependent manner, secreting its luminal contents, and ILVs, which are then called exosomes. Microglia normally act to clear extracellular A $\beta$, tau, and tau in exosomes. (Right) Alzheimer's pathogenic drivers accelerate the production of A $\beta$ by mutations in APP and its cleaving enzymes (early-onset AD), or by trafficking defects that slow APP flow out of the endosome (late-onset AD). These molecular and cellular defects lead to increased ILV formation in MVBs, which is postulated to increase tau localization in MVBs. Microglia defects, which increase AD risk, lead to reduced extracellular clearance. High connectivity is hypothesized to accelerate these pathogenic mechanisms by increasing synaptic activity, increasing APP endocytosis, and increasing ILV formation. High connectivity will also increase MVB fusion, leading to increased neuronal secretion. Tau and even $A \beta$ are known to spread via synaptic connections. Highly connected regions will accelerate this spread.

(Small and Gandy 2006; Rogaeva et al. 2007), are causally pathogenic in AD (Vardarajan et al. 2015; Verheijen et al. 2016). Additionally, the core retromer protein, VPS35, is deficient in regionally vulnerable AD brains (Small et al. 2005), and a rare de novo mutation in VPS35 has been identified (Rovelet-Lecrux et al. 2015). Finally, a range of other genetic variants encoding proteins that are part of each retromer module have been associated with $\mathrm{AD}$ (Vardarajan et al. 2012). Defects in SORL1 and other retromer-related molecules slow the trafficking of APP out of endosomes, and these defects cause accelerated $\mathrm{A} \beta$ production and secretion. So akin to defects in APP processing, defects in endosomal trafficking will interact with high synaptic activity in the EPBZ, accounting for its vulnerability.

The neuronal consequences of high synaptic activity can also interact with the mechanisms for how tau is secreted from neurons and perhaps even influence how it is processed in neurons. As reviewed above, there is little doubt that tau pathology starts in the EPBZ and more specifically in dendrites of the zone. Why would this be the case? Interestingly, a recent study suggests that endosomal trafficking defects, induced by manipulating retromer, can regulate tau pathology in IPC-derived human neurons, independent of $A \beta$ (Young et al. 2018). Additionally, some studies have shown that tau is highly expressed in the entorhinal area (Hu et al. 2017).
Although still untested, it is also possible that high activity interacts with the mechanisms that cause tau pathology, which might explain why tau accumulates in dendrites. Nevertheless, what is clear is that high activity increases the secretion of tau extracellularly (Yamada et al. 2014; Wu et al. 2016). The original formulation that tau is secreted into the extracellular space and the cerebrospinal fluid because of dying neurons is now believed to be wrong (Zetterberg 2017; Sato et al. 2018). It is now understood that tau is secreted in a regulated, activity-dependent, manner (Sato et al. 2018). Studies have shown that tau is not secreted via the conventional secretory pathway, but rather via "unconventional secretion" (Chai et al. 2012; Mohamed et al. 2014; Karch and Goate 2015), most likely_-just like $A \beta$ - via activity-dependent multivescular body (MVB) fusion (Fig. 3). Recent studies have solved the topological dilemma over how tau, a cytosolic protein, gains access to the endosomal system. Tau gains access to MVBs by a process called microautophagy, which is an invagination of the MVB membrane, scooping up cytosolic proteins in the process (Caballero et al. 2018). These membrane pockets inside the MVB, the intraluminal vesicles that gave MVBs its name, can then dissolve in the MBV (Caballero et al. 2018). The end result is that tau exists inside MVBs, in or out of intraluminal vesicles (ILVs). When MVBs fuse with the membrane, they release 
both contents. In the extracellular space ILVs are called exosomes.

Microglia defects, although not causative, significantly increase the risk of AD (Guerreiro et al. 2013; Karch and Goate 2015). Recent studies suggest that the APOE4 genotype confers its known risk to AD by interacting with microglia (Shi and Holtzman 2018). Although it remains unclear precisely how defective microglia affect AD risk, a dominant view is that it reduces the clearance of extracellular A $\beta$ and/or tau (Shi and Holtzman 2018), leading to increased extracellular levels.

\section{A NETWORK EXPLANATION FOR ALZHEIMER'S ANATOMICAL SPREAD}

In this section, we will offer a hypothesis for how the EPBZ's network properties can explain Alzheimer's anatomical pattern of spread. In developing the hypothesis, we begin with the fact that tau pathology starts in the EPBZ, and with two assumptions. First, although still debated, we assume that the mounting evidence in favor of tau's transsynaptic spread is at least in part correct (Walker et al. 2013). Second, because tau pathology begins in the dendrites of the superficial layers of the EPBZ (Braak et al. 2006), we assume that tau spreads retrogradely.

If the assumptions are true, the hypothesis would predict that, over time, the anatomical map of tau spread out of the EPBZ would follow its connectivity patterns and occur in two waves. The first wave, out of the EPBZ, would be largely restricted to the immediately adjacent, highly interconnected parts of the VTVZ, and then from the entire VTVZ the second tidal wave would distribute tau across broad cortical swaths. The observed pattern of tau spread, arranged according to progressive worsening stages of the disease, supports this prediction (Fig. 4; Braak et al. 2006).

How about the hippocampal region? Interestingly, among all hippocampal components the dentate gyrus is the one part that has the least tau pathology, and when observed occurs only in later disease stages (Fig. 4; Braak et al. 2006; Johnson et al. 2016). As the dentate gyrus

\section{Tau Map (Stage III)}
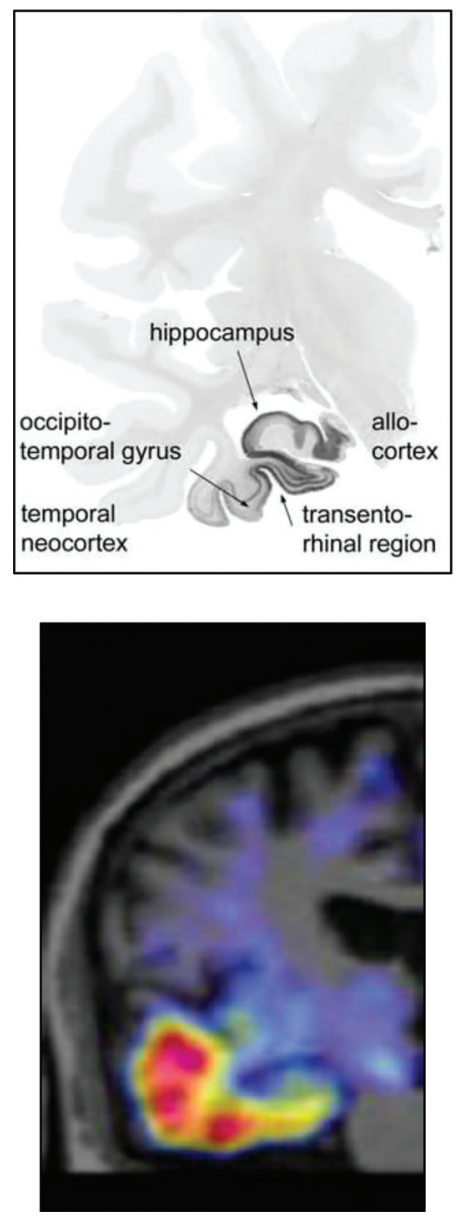

Tau Map (Stage IV)
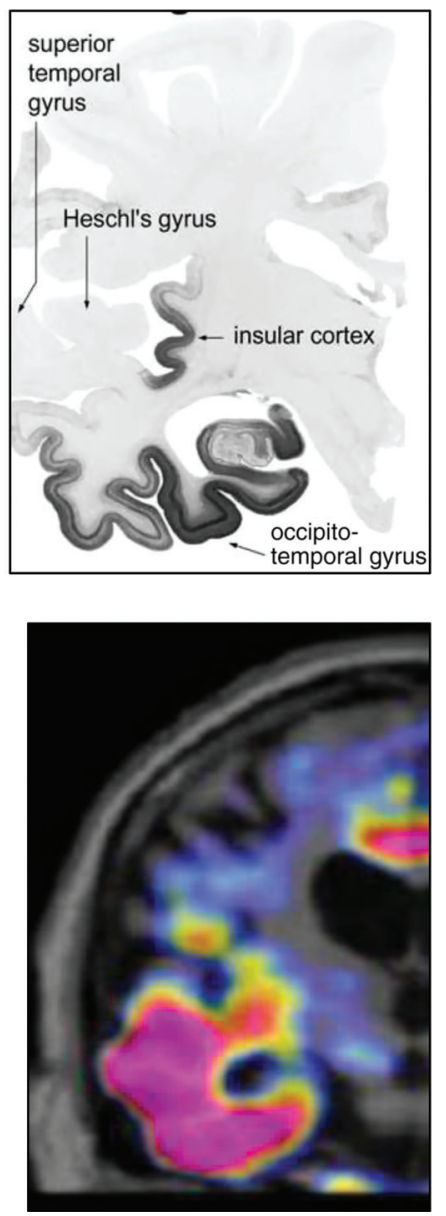

Tau Map (Stage VI)
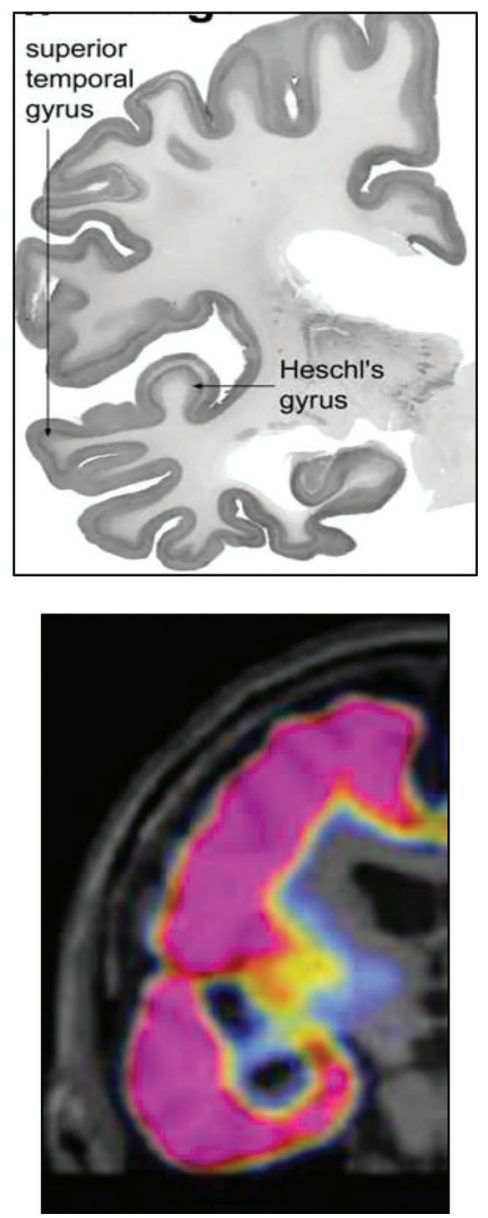

Figure 4. The anatomical pattern of tau spread supports the hypothesis. Postmortem mapping of tau pathology (upper panels) and neuromaging mapping of tau pathology (lower panels) are arranged according to the stages of the disease. Note that from stage III to stage IV tau spreads is largely restricted to brain regions immediately adjacent and highly interconnected with the EPBZ. From there, in later stages, tau spreads across broad cortical swaths (Upper, Reprinted from Braak et al. 2006, with permission from Springer Nature; lower, reprinted from Johnson et al. 2016, with permission from John Wiley and Sons.). 
receives a truly massive axonal input from superficial layers of the entorhinal area, this feature provides the strongest support for the assumption that tau does not spread anterogradely through axons. In contrast, field CA1 is the hippocampal component that shows the first and highest levels of tau pathology (Braak et al. 2006). This spread is typically observed, however, when tau appears in the deeper layers of the entorhinal area (Braak et al. 2006), layers that receive the strongest axonal inputs from field CA1.

Besides accounting for the observed pattern of tau spread, this hypothesis makes additional predictions. The amygdala is a region that is highly connected with the EPBZ, and so the hypothesis would predict that it too should have high tau in early stages of disease, especially in the basolateral nucleus. Although original tau maps have neglected the amygdala, recent studies have shown that this is exactly the case, in both patients (Mishra et al. 2017) and in animal models (Fu et al. 2016).

\section{CONCLUSION}

Understanding AD's regional vulnerability has remained one of the major mysteries in the field. Here we introduce a hypothesis for how the unique network properties of the EPBZ, AD's anatomical ground zero (Yassa 2014), interacts with AD's known pathogenic mechanisms in imposing regional vulnerability. Furthermore, this interaction can account for the anatomical pattern of disease spread.

The hypothesis is grounded in the established network organization of the cerebral cortex, on the one hand, and established pathogenic mechanisms on the other. As reviewed, empirical observations cohere with predictions of the hypothesis. The hypothesis generates a number of additional predictions, which if validated by future studies, will provide further evidence in its support, and have important clinical implications. The hypothesis assumes that most tau pathology observed throughout the course of the disease emanates primarily from the EPBZ. If true, then ameliorating AD-associated EPBZ pathology in the preclinical stages of the disease is predicted to arrest the anatomical spread of tau pathology. However, ameliorating AD-associated pathology selectively in the EPBZ is challenging. With recent advances in gene therapy, it will hopefully soon be possible to selectively target the EPBZ. By combining these gene therapy approaches with neuroimaging techniques that can detect AD-associated EPBZ pathology in this earliest of AD stages - and can track the anatomical spread of tau out of the EPBZ - this prediction can be tested.

A core neuronal assumption of the hypothesis is that the high afferent input onto the EPBZ induces high rates of endosomal trafficking, and that can explain why the EBPZ is vulnerable to AD's pathogenic mechanisms, causingamong other defects - high rates of extracellular release of $A \beta$ and tau. If true, then the EBPZ in normal brain should show cellular or molecular signatures of high endosomal trafficking rates. We note that by using a screening approach, the elements of the retromer were found selective- ly deficient in the entorhinal area of AD brains compared to dentate gyrus (Small et al. 2005). This study, however, did not examine the EPBZ more specifically. Moreover, this finding by itself does not argue that the EBPZ has high rates of endosomal trafficking. This prediction, therefore, requires future investigation.

\section{ACKNOWLEDGMENTS}

This study was partly supported by the Kavli Foundation and National Institutes of Health grant P50AG00 8702 .

\section{REFERENCES}

Ball MJ. 1978. Topographic distribution of neurofibrillary tangles and granulovacuolar degeneration in hippocampal cortex of aging and demented patients. A quantitative study. Acta Neuropathol 42: 73-80. doi:10.1007/BF00690970

Boccara CN, Kjonigsen LJ, Hammer IM, Bjaalie JG, Leergaard TB, Witter MP. 2015. A three-plane architectonic atlas of the rat hippocampal region. Hippocampus 25: 838-857. doi: 10.1002/hipo. 22407

Bota M, Sporns O, Swanson LW. 2015. Architecture of the cerebral cortical association connectome underlying cognition. Proc Natl Acad Sci 112: E2093-E2101. doi:10.1073/ pnas. 1504394112

Braak H, Braak E. 1991. Neuropathological stageing of Alzheimer-related changes. Acta Neuropathol 82: 239-259. doi:10.1007/BF00308809

Braak H, Del Tredici K, Rub U, de Vos RA, Jansen Steur EN, Braak E. 2003. Staging of brain pathology related to sporadic Parkinson's disease. Neurobiol Aging 24: 197-211.

Braak H, Alafuzoff I, Arzberger T, Kretzschmar H, Del Tredici K. 2006. Staging of Alzheimer disease-associated neurofibrillary pathology using paraffin sections and immunocytochemistry. Acta Neuropathol 112: 389-404. doi:10.1007/s00401-0060127-z

Brickman A, Stern Y, Small S. 2010. Hippocampal subregions differentially associate with standard memory tests. Hippocampus 21: 923-928. doi:10.1002/hipo.20840

Caballero B, Wang Y, Diaz A, Tasset I, Juste YR, Stiller B, Mandelkow EM, Mandelkow E, Cuervo AM. 2018. Interplay of pathogenic forms of human tau with different autophagic pathways. Aging Cell 17. doi:10.1111/acel.12692

Chai X, Dage JL, Citron M. 2012. Constitutive secretion of tau protein by an unconventional mechanism. Neurobiol Dis 48: 356-366. doi:10.1016/j.nbd.2012.05.021

Cirrito JR, Kang JE, Lee J, Stewart FR, Verges DK, Silverio LM, Bu G, Mennerick S, Holtzman DM. 2008. Endocytosis is required for synaptic activity-dependent release of amyloid- $\beta$ in vivo. Neuron 58: 42-51. doi:10.1016/j.neuron.2008. 02.003

Elias MF, Beiser A, Wolf PA, Au R, White RF, D'Agostino RB. 2000. The preclinical phase of Alzheimer disease: a 22-year prospective study of the Framingham Cohort. Arch Neurol 57: 808-813. doi:10.1001/archneur.57.6.808

Fu H, Hussaini SA, Wegmann S, Profaci C, Daniels JD, Herman M, Emrani S, Figueroa HY, Hyman BT, Davies P, et al. 2016. $3 \mathrm{D}$ visualization of the temporal and spatial spread of tau pathology reveals extensive sites of tau accumulation associated with neuronal loss and recognition memory deficit in aged tau transgenic mice. PLoS One 11: e 0159463.

Gómez-Isla T, Price JL, McKeel DW Jr, Morris JC, Growdon JH, Hyman BT. 1996. Profound loss of layer II entorhinal cortex neurons occurs in very mild Alzheimer's disease. J Neurosci 16: 4491-4500. doi:10.1523/JNEUROSCI.16-14-04491. 1996 
Gouras GK, Tampellini D, Takahashi RH, Capetillo-Zarate E. 2010. Intraneuronal $\beta$-amyloid accumulation and synapse pathology in Alzheimer's disease. Acta Neuropathol 119: 523 541. doi:10.1007/s00401-010-0679-9

Guerreiro R, Wojtas A, Bras J, Carrasquillo M, Rogaeva E, Majounie E, Cruchaga C, Sassi C, Kauwe JS, Younkin S, et al. 2013. TREM2 variants in Alzheimer's disease. $N$ Engl $J$ Med 368: 117-127. doi:10.1056/NEJMoa1211851

Hardy J, Selkoe DJ. 2002. The amyloid hypothesis of Alzheimer's disease: progress and problems on the road to therapeutics. Science 297: 353-356. doi:10.1126/science .1072994

Hu W, Wu F, Zhang Y, Gong CX, Iqbal K, Liu F. 2017. Expression of tau pathology-related proteins in different brain regions: a molecular basis of tau pathogenesis. Front Aging Neurosc 9: 311.

Johnson KA, Schultz A, Betensky RA, Becker JA, Sepulcre J, Rentz D, Mormino E, Chhatwal J, Amariglio R, Papp K, et al. 2016. Tau positron emission tomographic imaging in aging and early Alzheimer disease. Ann Neurol 79: 110-119. doi:10.1002/ana.24546

Karch CM, Goate AM. 2015. Alzheimer's disease risk genes and mechanisms of disease pathogenesis. Biol Psychiatry 77: 4351. doi:10.1016/j.biopsych.2014.05.006

Khan UA, Liu L, Provenzano FA, Berman DE, Profaci CP, Sloan R, Mayeux R, Duff KE, Small SA. 2014. Molecular drivers and cortical spread of lateral entorhinal cortex dysfunction in preclinical Alzheimer's disease. Nat Neurosci 17: 304-311. doi:10.1038/nn.3606

Lue LF, Kuo YM, Roher AE, Brachova L, Shen Y, Sue L, Beach T, Kurth JH, Rydel RE, Rogers J. 1999. Soluble amyloid $\beta$ peptide concentration as a predictor of synaptic change in Alzheimer's disease. Am J Pathol 155: 853-862. doi: 10.1016/S0002-9440(10)65184-X

Maass A, Lockhart SN, Harrison TM, Bell RK, Mellinger T, Swinnerton K, Baker SL, Rabinovici GD, Jagust WJ. 2018 Entorhinal tau pathology, episodic memory decline, and neurodegeneration in aging. J Neurosci 38: 530-543. doi: 10.1523/JNEUROSCI.2028-17.2017

Mishra S, Gordon BA, Su Y, Christensen J, Friedrichsen K, Jackson K, Hornbeck R, Balota DA, Cairns NJ, Morris JC, et al. 2017. AV-1451 PET imaging of tau pathology in preclinical Alzheimer disease: defining a summary measure. Neuroimage 161: 171-178. doi:10.1016/j.neuroimage.2017.07 .050

Mohamed NV, Plouffe V, Rémillard-Labrosse G, Planel E, Leclerc N. 2014. Starvation and inhibition of lysosomal function increased tau secretion by primary cortical neurons. $\mathrm{Sci}$ Rep 4: 5715. doi:10.1038/srep05715

Rajendran L, Honsho M, Zahn TR, Keller P, Geiger KD, Verkade P, Simons K. 2006. Alzheimer's disease $\beta$-amyloid peptides are released in association with exosomes. Proc Natl Acad Sci 103: 11172-11177. doi:10.1073/pnas.0603838103

Rogaeva E, Meng Y, Lee JH, Gu Y, Kawarai T, Zou F, Katayama T, Baldwin CT, Cheng R, Hasegawa H, et al. 2007. The neuronal sortilin-related receptor SORL1 is genetically associated with Alzheimer disease. Nat Genet 39: 168-177. doi:10.1038/ ng1943

Rovelet-Lecrux A, Charbonnier C, Wallon D, Nicolas G, Seaman MN, Pottier C, Breusegem SY, Mathur PP, Jenardhanan P, Le Guennec K, et al. 2015. De novo deleterious genetic variations target a biological network centered on $\mathrm{A} \beta$ peptide in earlyonset Alzheimer disease. Mol Psychiatry 20: 1046-1056. doi: $10.1038 / \mathrm{mp} .2015 .100$

Sato C, Barthélemy NR, Mawuenyega KG, Patterson BW, Gordon BA, Jockel-Balsarotti J, Sullivan M, Crisp MJ, Kasten T, Kirmess KM, et al. 2018. Tau kinetics in neurons and the human central nervous system. Neuron 98: 861-864. doi: 10.1016/j.neuron.2018.04.035

Savina A, Fader CM, Damiani MT, Colombo MI. 2005. Rab11 promotes docking and fusion of multivesicular bodies in a calcium-dependent manner. Traffic 6: 131-143. doi:10.1111/ j.1600-0854.2004.00257.x
Schöll M, Lockhart SN, Schonhaut DR, O’Neil JP, Janabi M, Ossenkoppele R, Baker SL, Vogel JW, Faria J, Schwimmer $\mathrm{HD}$, et al. 2016. PET imaging of tau deposition in the aging human brain. Neuron 89: 971-982. doi:10.1016/ j.neuron.2016.01.028

Selkoe DJ. 2002. Alzheimer's disease is a synaptic failure. Science 298: 789-791. doi:10.1126/science.1074069

Shi Y, Holtzman DM. 2018. Interplay between innate immunity and Alzheimer disease: APOE and TREM2 in the spotlight. Nat Rev Immunol doi:10.1038/s41577-018-0051-1

Small SA, Gandy S. 2006. Sorting through the cell biology of Alzheimer's disease: intracellular pathways to pathogenesis. Neuron 52: 15-31. doi:10.1016/j.neuron.2006.09.001

Small SA, Petsko GA. 2015. Retromer in Alzheimer disease, Parkinson disease and other neurological disorders. Nat Rev Neurosci 16: 126-132. doi:10.1038/nrn3896

Small SA, Kent K, Pierce A, Leung C, Kang MS, Okada H, Honig L, Vonsattel JP, Kim TW. 2005. Model-guided microarray implicates the retromer complex in Alzheimer's disease. Ann Neurol 58: 909-919. doi:10.1002/ana.20667

Small SA, Simoes-Spassov S, Mayeux R, Petsko GA. 2017. Endosomal traffic jams represent a pathogenic hub and therapeutic target in Alzheimer's disease. Trends Neurosci 40: 592 602. doi:10.1016/j.tins.2017.08.003

Sperling R, Mormino E, Johnson K. 2014. The evolution of preclinical Alzheimer's disease: implications for prevention trials. Neuron 84: 608-622. doi:10.1016/j.neuron.2014.10 .038

Stepanyants A, Hof PR, Chklovskii DB. 2002. Geometry and structural plasticity of synaptic connectivity. Neuron 34: 275-288. doi:10.1016/S0896-6273(02)00652-9

Swanson LW. 2015. Neuroanatomical terminology: a lexicon of classical origins and historical foundations. Oxford University Press, New York.

Swanson LW. 2018. Brain maps 4.0-Structure of the rat brain: an open access atlas with global nervous system nomenclature ontology and flatmaps. J Comp Neurol 526:935-943. doi: $10.1002 /$ cne. 24381

Swanson LW, Hahn JD, Sporns O. 2017. Organizing principles for the cerebral cortex network of commissural and association connections. Proc Natl Acad Sci 114: E9692-E9701. doi: 10.1073/pnas. 1712928114

Swanson LW, Hahn JD, Jeub LGS, Fortunato S, Sporns O. 2018. Subsystem organization of axonal connections within and between the right and left cerebral cortex and cerebral nuclei (endbrain). Proc Natl Acad Sci 115: E6910-E6919. doi: 10.1073/pnas. 1807255115

Tomic JL, Pensalfini A, Head E, Glabe CG. 2009. Soluble fibrillar oligomer levels are elevated in Alzheimer's disease brain and correlate with cognitive dysfunction. Neurobiol Dis 35: 352-358. doi:10.1016/j.nbd.2009.05.024

Tward DJ, Sicat CS, Brown T, Bakker A, Gallagher M, Albert M, Miller M. 2017. Entorhinal and transentorhinal atrophy in mild cognitive impairment using longitudinal diffeomorphometry. Alzheimers Dement (Amst) 9: 41-50. doi:10.1016/j.dadm. 2017.07.005

Vardarajan BN, Bruesegem SY, Harbour ME, St George-Hyslop P, Seaman MN, Farrer LA. 2012. Identification of Alzheimer disease-associated variants in genes that regulate retromer function. Neurobiol Aging 33: 2231.e15-2231.e30. doi: 10.1016/j.neurobiolaging.2012.04.020

Vardarajan BN, Zhang Y, Lee JH, Cheng R, Bohm C, Ghani M, Reitz C, Reyes-Dumeyer D, Shen Y, Rogaeva E, et al. 2015. Coding mutations in SORL1 and Alzheimer disease. Ann Neurol 77: 215-227. doi:10.1002/ana.24305

Verheijen J, Van den Bossche T, van der Zee J, Engelborghs S, Sanchez-Valle R, Lladó A, Graff C, Thonberg H, Pastor P, Ortega-Cubero S, et al. 2016. A comprehensive study of the genetic impact of rare variants in SORL1 in European early-onset Alzheimer's disease. Acta Neuropathol 132: 213-224.

Walker LC, Diamond MI, Duff KE, Hyman BT. 2013. Mechanisms of protein seeding in neurodegenerative diseases. 
JAMA Neurol 70: 304-310. doi:10.1001/jamaneurol.2013 .1453

Wu JW, Hussaini SA, Bastille IM, Rodriguez GA, Mrejeru A, Rilett K, Sanders DW, Cook C, Fu H, Boonen RA, et al. 2016. Neuronal activity enhances tau propagation and tau pathology in vivo. Nat Neurosci 19: 1085-1092. doi:10.1038/nn.4328

Yamada K, Holth JK, Liao F, Stewart FR, Mahan TE, Jiang H, Cirrito JR, Patel TK, Hochgräfe K, Mandelkow EM, et al. 2014. Neuronal activity regulates extracellular tau in vivo. J Exp Med 211: 387-393. doi:10.1084/jem.2013 1685
Yassa MA. 2014. Ground zero in Alzheimer's disease. Nat Neurosci 17: 146-147. doi:10.1038/nn.3631

Young JE, Fong LK, Frankowski H, Petsko GA, Small SA, Goldstein LSB. 2018. Stabilizing the retromer complex in a human stem cell model of Alzheimer's disease reduces TAU phosphorylation independently of amyloid precursor protein. Stem Cell Reports 10: 1046-1058. doi:10.1016/j.stemcr.2018.01.031

Zetterberg H. 2017. Review: tau in biofluids-relation to pathology, imaging and clinical features. Neuropathol Appl Neurobiol 43: 194-199. doi:10.1111/nan.12378 


\section{$\$_{\text {CSH }}^{\infty}$ Cold Spring Harbor Symposia SYMPOSIA On Quantitative Biology}

\section{A Network Explanation of Alzheimer's Regional Vulnerability}

Scott A. Small and Larry W. Swanson

Cold Spring Harb Symp Quant Biol 2018 83: $193-200$ originally published online January 14, 2019

Access the most recent version at doi:10.1101/sqb.2018.83.036889

References This article cites 52 articles, 9 of which can be accessed free at: http://symposium.cshlp.org/content/83/193.full.html\#ref-list-1

Creative This article is distributed under the terms of the

Commons http://creativecommons.org/licenses/by-nc/4.0/, which permits reuse and License redistribution, except for commercial purposes, provided that the original author and source are credited.

Email Alerting Receive free email alerts when new articles cite this article - sign up in Service the box at the top right corner of the article or click here. 